\title{
Cooperative Learning, Jigsaw Strategies, And Reflections Of Graduate And Undergraduate Education Students
}

Bobbette M. Morgan, (Email: Bobbette.Morgan@utb.edu), University of Texas at Brownsville and Texas Southmost College Alma D. Rodríguez, University of Texas at Brownsville and Texas Southmost College

Graciela P. Rosenberg, University of Texas at Brownsville and Texas Southmost College

\begin{abstract}
Classes of undergraduate and graduate students assigned to three professors were used to experience cooperative learning, jigsaw strategies, and to reflect on the process that occurred over a semester. The work is based upon theories of social interdependence, cognitive development, and behavioral learning. Pre- and post surveys were completed by 23 graduate and 57 undergraduate education students to compare and contrast knowledge about their experiences working cooperatively and specifically in a jigsaw format that included the role of expert, preparation pairs, and in groups of three where positive interdependence is structured through resource interdependence with a summary by the professor. Anonymous student reflections about their experiences were also collected. Results are analyzed and shared. Cooperative learning requires much more than simply putting students in groups as many university education students believe. By giving undergraduate and graduate students the opportunity to work in jigsaw groups this project increased the awareness of the pre-service and in-service educators concerning cooperative groups using structured jigsaws. As they experienced challenges in working cooperatively themselves, they began to discuss and plan how these challenges might occur with K-12 students and how the challenges could be met through how they design lessons for their classrooms.
\end{abstract}

\section{PURPOSE}

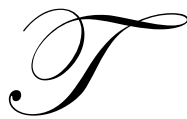

he purpose of the research is to share results regarding the perception of higher education students and their experiences with cooperative learning and jigsaw activities. The convenient sample consisted of 57 undergraduate and 23 graduate students enrolled in three different professors' education courses. Participants were primarily first and second-generation immigrants from Mexico, South America, and Cuba and are often the first in their family to attend college.

\section{PERSPECTIVES}

The theoretical framework for this paper centers on cooperative learning. Cooperative learning has its roots in the theories of social interdependence, cognitive development, and behavioral learning. Some research provides exceptionally strong evidence that cooperative learning results in greater effort to achieve, more positive relationships, and greater psychological health than competitive or individualistic learning efforts (Johnson, Johnson, \& Holubec, 1994).

Social interdependence theory views cooperation as resulting from positive links of individuals to accomplish a common goal. The Gesalt psychologist Kurt Koffka proposed in the early 1900's that although groups are dynamic wholes the interdependence among members is variable. Kurt Lewin (1948) stated that interdependence from common goals provides the essential essence of a group. This interdependence creates groups that are dynamic wholes. The power of the group is such that a change in any member or subgroup directly changes any other member or subgroup.

Within cognitive development theory, cooperation must precede cognitive growth. Cognitive growth springs from the alignment of various perspectives as individuals work to attain common goals. Both Piaget and Vygotsky saw 
cooperative learning with more able peers and instructors as resulting in cognitive development and intellectual growth (Johnson, Johnson, \& Smith, 1998).

The assumption of behavioral learning theory is that students will work hard on tasks that provide a reward and that students will fail to work on tasks that provide no reward or punishment. Cooperative learning is one strategy that rewards individuals for participation in the group's effort.

A review of the literature on cooperative learning shows that students benefit academically and socially from cooperative, small-group learning (Gillies, 2002). Cooperative learning can produce positive effects on student achievement (Cohen, 1986; Davidson, 1989; Devries \& Slavin, 1978; Johnson \& Johnson, 1989; Okebukola, 1985; Reid, 1992; Slavin, 1990). Academic benefits include higher attainments in reading comprehension (Mathes, Fuchs, \& Fuchs, 1997) and mathematics (Ross, 1995; Whicker, Nunnery, \& Bol, 1997) and enhanced conceptual understanding and achievement in science (Lonning, 1993; Watson, 1991). Social benefits include more on-task behaviors and helping interactions with group members (Burron, James, \& Ambrosio, 1993; Gillies \& Ashman, 1998; McManus \& Gettinger, 1996), higher self-esteem, more friends, more involvement in classroom activities, and improved attitudes toward learning (Lazarowitz, Baird, \& Bolden, 1996; Lazarowitz, Hertz-Lazarowitz, \& Baird, 1994).

According to Emmer and Gerwels (2002) some research on cooperative learning has addressed instructional components. In a number of studies students have been taught interaction skills, such as how to question or to help each other so that they did not give answers but facilitated each other's thinking (Fuchs, Fuchs, Kazdan, \& Allen, 1999; Gillies \& Ashman, 1996, 1998; Nattiv, 1994; Webb, Troper, \& Fall, 1995). And, when students are taught such skills, positive outcomes such as increased intrinsic motivation, liking for school, and self-esteem can result (Battistich, Solomon, \& Delucchi, 1993).

A review of recent literature on jigsaw structures reveals this cooperative learning structure has both social and academic benefits. Jigsaw II increases students' motivation to read (Shaaban, 2006). The use of the Jigsaw increases students' self-esteem, individual and group responsibility, mutual assistance, friendship relationships and verbal communication (Santos Rego \& Lorenzo Moledo, 2005). Ghaith and Bouzeineddine (2003) encourage the use of Jigsaw II activities to improve the attitudes and academic achievement ofunderachieving students. Elmore and Zenus (1994) advocate the use of cooperative learning with gifted students to positively impact their self-esteem. Students who experience Jigsaw II cooperative learning activities increase their higher order reading comprehension skills. The use of summarization, processing, and explanation of information to others, results in the development of deeper comprehension of reading material (Ghaith \& El-Malak, 2004). The use of jigsaw structures resulted also in both perceived and actual achievement of faculty members who participated in a seminar on cooperative learning (Lindquist, 1997).

\section{METHODS AND DATA SOURCES}

Data collection for this mixed methodology study occurred over an academic semester with students attending a community university. Graduate and undergraduate students were asked to complete pre- and post surveys. The surveys included three different types of questions. Students were asked to rate their knowledge of cooperative learning and jigsaw strategies on a Likert-type scale of one to five, they were asked to describe their experiences with cooperative learning and jigsaws, and they were asked to define specific terms related to cooperative learning: the five elements of the Johnson and Johnson model. The majority of the survey items are from a teacher survey developed by Johnson and Johnson. The consistency of questions and possible response options on the pre- and post course surveys allowed researchers to make comparisons about students' knowledge of cooperative learning and perceptions of expertise before, during, and after the course (Fraenkel \& Wallen, 1996).

Undergraduate and graduate students were also asked to reflect on their experiences during the semester, using the following open-ended questions:

- What are your beliefs regarding cooperative learning?

- Have you used cooperative learning in a lesson? Were you able to see the students cooperating during the lesson? Give an example.

- $\quad$ Describe your experience with the jigsaw strategy. 
The use of standardized open-ended questions allowed the researchers to focus the students' attention on certain topics of interest without limiting the possible responses. It also allowed the researchers to gather data from the perspective of the undergraduate and graduate students (Patton, 1990). The reflections and responses were analyzed using an inductive approach. The researchers searched for patterns in the data and then categorized the data according to the patterns that emerged (Krathwohl, 1993).

The researchers analyzed the data and searched for patterns separately. Then they shared the categories that they had found in the research and further refined their categories, thus providing a peer check of the analysis (Carspecken, 1996). Multiple data sources and peer checks were used to triangulate the emerging findings and to contribute to the credibility of the study (Patton, 1990).

At the end of the research study, participants were asked to respond in writing to the written prompts asking them to share what they had learned from working in jigsaw groups. Additionally, pre- and post surveys gathered data related to cooperative learning strategies and self-reporting about use and experiences with the jigsaw strategies.

\section{RESULTS}

Results of the pre- and post- survey, that included Likert-type responses, were summarized for all 30 questions. Using SPSS software, graduate and undergraduate students' responses were compared. Only one item of 30 indicated a level of significance on the Levene's Test for Equality of Variances using the 2-tailed t-test for equality of means. Since there is a one in twenty chance of inaccuracy the researchers determined that there was no significant difference between the graduate and undergraduate student responses.

This supports the researchers' experience that many educators come into instructional strategy classes thinking that they know what cooperative learning is, but really are doing grouping with their students, not cooperative learning.

Because there was no significant difference found between graduate and undergraduate students the data for the two groups was combined and reviewed for levels of significance using Levene's Test for Equality of Variances on a 2tailed t-test for Equality of Means where equal variances are assumed and $p<.05$ for the total pre- and post survey results. One question required students to define the five elements of cooperative learning based on the Johnson and Johnson model.

Fifteen of the thirty items were significant at $p<.05$. Following is a chart of the significant items between the preand post survey results based on Levene's Test for Equality of Variances on a two-tailed t-test for Equality of Means where equal variances are assumed and $p<.05$.

\begin{tabular}{|c|l|c|}
\hline Item & \multicolumn{1}{|c|}{ Statement } & $\begin{array}{c}\text { Significance } \\
\text { (2-tailed) }\end{array}$ \\
\hline B & I have read articles about cooperative learning. & .001 \\
\hline $\mathbf{C}$ & $\begin{array}{l}\text { I have discussed cooperative learning with other educators or classmates and tried some of their ideas in the } \\
\text { classroom. }\end{array}$ & .000 \\
\hline G & I have participated in a university credit course and learned about cooperative learning. & .000 \\
\hline $\mathbf{2 .}$ & I believe that cooperative learning increases student participation in learning activities. & .044 \\
\hline $\mathbf{3 .}$ & I believe that cooperative learning improves student communication and decision making skills. & .010 \\
\hline $\mathbf{4 .}$ & I believe that cooperative learning encourages and improves the performance of high ability students. & .033 \\
\hline $\mathbf{9 .}$ & Rewarding individual performance based on group success is an equitable method of grading. & .000 \\
\hline $\mathbf{1 1 .}$ & How would you rate your theoretical knowledge regarding cooperative learning? & .002 \\
\hline $\mathbf{1 2 .}$ & $\begin{array}{l}\text { How would you rate your knowledge regarding the effective implementation of cooperative learning as a model } \\
\text { of teaching? }\end{array}$ & .000 \\
\hline $\mathbf{1 3 .}$ & $\begin{array}{l}\text { When we work together in small groups, we try to make sure that everyone in our group learns all of the } \\
\text { assigned material. }\end{array}$ & .031 \\
\hline $\mathbf{1 4 .}$ & When we work together in small groups, we cannot complete an assignment unless everyone contributes. & .000 \\
\hline $\mathbf{1 5 .}$ & $\begin{array}{l}\text { When we work together in small groups, our job is not done until everyone in our group has finished the } \\
\text { assignment. }\end{array}$ & .002 \\
\hline $\mathbf{2 8 .}$ & Working in a jigsaw helps me learn assigned material. & .010 \\
\hline $\mathbf{2 9}$. & As an "expert" for part of the material we need to learn, makes me prepare more carefully. & .001 \\
\hline
\end{tabular}


Responses to the open-ended reflection questions provided the researchers with important insights. The first question asked the participants to state their beliefs regarding cooperative learning. One hundred percent of graduate and ninety-three percent of undergraduate students considered cooperative learning to be an effective model of teaching. They stated that students benefit from learning from their peers. They stressed the benefits of students discussing material and improving their communication and social skills as they acquire new knowledge. One of the participants stated, "I believe cooperative learning is a great way for students to develop their communication skills and at the same time learn course material." They also stated that cooperative learning promotes the exchange of ideas. A participant stated that "it allows several view points to get across and for students to learn from each other." A good number of participants considered cooperative learning beneficial for struggling students as they are encouraged by more capable peers to do their best. One of these participants stated that cooperative learning "gives students confidence" and that it is a "good way to teach because it benefits all students, especially the low achievers."

The participants became aware of the importance of grouping students heterogeneously so that low ability students experience success as they work with high achievers. A good number of graduate participants stated the importance of structuring cooperative learning effectively in order to get positive results. They stressed the importance of teacher preparation and planning. As one participant stated, teachers "need to be consistent." The participants realized the importance of cooperative learning being "done correctly to be successful." Overall, they believe that "cooperative learning works well with students when the guidelines of participation are established, well demonstrated and practiced."

The second reflection question asked participants to state if they had used cooperative learning in a lesson and to explain what they had observed during that lesson. Ninety-one percent of graduate students and thirty-five percent of undergraduate students indicated that they had used cooperative learning and observed students cooperating during lessons. The undergraduate participants had seen their mentor teachers implement cooperative learning and had noticed that students were "very excited" and motivated by the activities. They also observed students collaborating as they "shared their expertise with other group members." The graduate participants also observed that students collaborated and were motivated by the lesson. They specifically noted that low achieving students were helped and encouraged by their peers. One participant stated, "I was amazed...Not only did they help out each other, they showed motivation...I have heard comments like 'good job', and 'way to go'."

The third refection question asked the participants to describe their experience with the jigsaw strategy. Eightythree percent of graduate students and eighty-six percent of undergraduate students indicated that the jigsaw activities were positive experiences. They considered the jigsaw a good strategy to share and discuss ideas while learning. Many found the experience to be "fun and engaging." Moreover, the participants stated that the jigsaw strategy allowed them to understand and retain the information. One participant stated, "I grasped concepts better because my peers explained parts of what we were learning to me. Since we talked about different areas and reflected, a greater amount of what we learned stayed with me." Unfortunately a few participants experienced some challenges with the jigsaw strategy. Some expressed an inability to concentrate while going over the materials to become experts. Others expressed a lack of trust on the ability of their group members to provide them with all the important information. Nevertheless, a few participants who were reluctant to working cooperatively changed their minds after experiencing the jigsaw strategy. One participant pointed out the following, "At first I thought the jigsaw strategy would not work. However, after experiencing it ... I realize it does have a positive effect on what you learn."

\section{EDUCATIONAL IMPORTANCE}

This study brings forth information about cooperative learning, jigsaw experiences and perceptions of students enrolled in courses within a university school of education. The 57 undergraduate and 23 graduate students were involved in the project over the period of a semester.

The results of this study show that participants had significant gains in their theoretical knowledge about cooperative learning. The participants realized that cooperative learning improves student participation, communication and performance. It is important to note that most of the 57 pre-service and 23 in-service educators felt comfortable using jigsaw strategies in the college classroom even though this was a new method for many of them. Another important finding was that participants realized that cooperative learning, jigsaws need to be structured correctly in order to be effective. They 
learned the difference between group work and cooperative learning since they were very precise in stating that cooperative learning has to be carefully planned and implemented.

The results of this study will add to the body of knowledge about use of cooperative learning and jigsaw with preservice and in-service educators, pre- and post self-reporting, and reflections about experiencing and implementing these learning strategies.

\section{REFERENCES}

1. Carspecken, P. F. (1996). Critical ethnography in educational research: A theoretical and practical guide. New York: Routledge.

2. $\quad$ Elmore, R. F. \& Zenus, V. (1994). Enhancing social-emotional development of middle school gifted students. Roeper Review, 16. Retrieved March 28, 2007 from Academic Search Premier.

3. Fraenkel, J. R. \& Wallen, N. E. (1996). How to design and evaluate research in education ( ${ }^{r d}$ ed.). New York: McGraw-Hill.

4. Ghaith, G. M. \& Bouzeineddine, A. R. (2003) Relationship between reading attitudes, achievement, and learners' perceptions of their Jigsaw II cooperative learning experience. Reading Psychology, 24, 105-121.

5. Ghaith, G. \& El-Malak, M. A. (2004). Effect of Jigsaw II on literal and higher order EFL reading comprehension. Educational Research and Evaluation, 10. 105-115.

6. Johnson, R. T. \& Johnson, D. W. (1994). An overview of cooperative learning. Retreived June 3, 2004 from http://www.co-operation.org

7. Johnson, D., Johnson, R., \& Holubec, E. (1994). Cooperative learning in the classroom. Alexandria, VA: Association for Supervision and Curriculum Development.

8. Johnson, D., Johnson R., \& Smith, K. (1998). Cooperative learning returns to college. Change. 30 (4): 26-35.

9. Krathwohl, D. R. (1993). Methods of educational and social science research: An integrated approach. New York: Longman.

10. Lewin, K. (1948). Resolving social conflicts. New York: Harper.

11. Lindquist, T. M. (1997). An experimental test of cooperative learning with faculty members as subjects. Journal of Education for Business, 72, 157-163.

12. Patton, M. (1990). Qualitative evaluation and research methods $\left(2^{\text {nd }}\right.$ ed.). Newbury Park, CA: SAGE Publications, Inc.

13. Shaaban, K. (2006). An initial study of the effects of cooperative learning on reading comprehension, vocabulary acquisition, and motivation to read. Reading Psychology, 27, 377-403.

14. Santos Rego, M. A. \& Lorenzo Moledo, M. M. (2005). Promoting interculturality in Spain: Assessing the use of the Jigsaw classroom method. Intercultural Education, 16, 293-301. 


\section{NOTES}

